\title{
What's wrong with business ethics
}

\author{
David Rodin
}

The field of business ethics is trapped between two competing and flawed conceptions of corporate responsibility. On the one hand is the shareholder value model, famously championed by Nobel Prize winning economist Milton Friedman, which claims that corporations owe positive moral obligations only to their shareholders (Friedman, 1993). On the other hand is the normative stakeholder theory, which claims that corporations are morally obliged to secure the interests of a broad range of groups, of which shareholders are only one. In this paper I will argue that if it is to generate a viable account of corporate moral responsibility, business ethics will need to abandon both canonical approaches and adopt a new approach based on a more concrete conception of the business corporation. Moreover this argument has important consequences for Michael Porter's influential approach to competitive strategy.

The stakeholder theory

David Rodin is Leverhulme Research Fellow at the Oxford Uehiro Centre for Practical Ethics, Oxford University and Senior Research Fellow at the Centre for Applied Philosophy and Public Ethics, the Australian National University. Previously he worked with the Boston Consulting Group, a global management consulting firm, and was a Rhodes Scholar from New Zealand. His research covers a broad range of issues in business ethics, international justice and the ethics of war and conflict. His book, War and SelfDefense (Oxford University Press 2002), was awarded the American Philosophical Association Frank Chapman Sharp Prize for the best monograph on the philosophy of war and peace.

Email: david.rodin@philosophy.oxford. ac.uk of the corporation has be-

come something of an orthodoxy in business ethics circles. It has become a standard feature of academic discussions and has been explicitly endorsed by several influential business organizations including the UK Business Round Table. In what follows I aim to cast doubt on the picture of the corporation that the stakean account of corporate moral responsibility (or as it is more often called in the literature, corporate social responsibility). What I mean by this is that we want to explain, not simply how particular persons may have moral obligations while operating in a business context, but how corporations themselves may be subject to moral obligations; obligations 
which in turn may serve as the ground for obligations of particular persons such as managers, employees, or board members. The idea of corporate moral responsibility is an important part of our pre-theoretical understanding of business ethics. We often say, for example, that the fact that a corporation ought, or ought not, to do something is the reason why a manager ought to behave in a particular way. If such a conception of corporate responsibility, as opposed to ethics in business, is to be vindicated then two prerequisites must be met. The first is that it must be possible to give an account of corporations as intentional agents. They must be construed as entities capable of deliberating, intending and acting. Second, corporations must be such as to be susceptible to reward and punishment because determining the appropriate distribution of reward and punishment is a central function of the concept of responsibility. For this to be the case, corporations must have substantive interests as well as being intentional agents. We will return to these two criteria below.

\section{Normative stakeholder theory}

Not all theories which ascribe moral significance to stakeholders are committed to what I shall refer to as the "normative stakeholder theory of the firm" ("stakeholder theory" for short). Any view which sees either managers or corporations as subject to moral obligations must specify the groups or individuals to which those obligations are owed. The groups commonly referred to as "stakeholders" (typically owners, managers, employees, suppliers, customers, and local communities) are obvious candidates. It is reasonable to assume that if a corporation has moral obligations to anyone, then it has obligations towards its stakeholders. Understood in this way, the notion of a stakeholder is simply a useful label for the primary objects of moral obligations in business contexts, but tells us nothing about the nature, grounds, or extent of those obligations.

In contrast to this rather modest claim, the stakeholder theory makes a much stronger claim about the function and purposes of the corporation itself. Here I will focus on the stakeholder theory of Ed Freeman and William Evan who were among the first and most influential writers to articulate this position. The distinguishing claim of stakeholder theory, according to Freeman and Evans, is that "The corporation should be managed for the benefit of its stakeholders" and that "The very purpose of the firm is (...) to serve as a vehicle for coordinating stakeholder interests" (Evan \& Freeman 1996, p. 262).

This claim is much stronger than the moderate view canvassed above, because that view is consistent with allowing that the fundamental purpose of the corporation is to further the interests of a particular group such as the shareholders, subject perhaps to the constraints of negative moral and legal obligations owed to other stakeholders (for example the obligation not to violate their human and other rights). Stakeholder theory, on the other hand, goes further because it denies shareholders any privileged position within the corporation. They are considered to be merely one stakeholder amongst others. The job of management is alternately described as being to "maximize" and to "balance" the interests of all such stakeholder groups.

Freeman defines a stakeholder in the following terms: "A stakeholder in an organization is (by definition) any group or individual who can affect or is affected by the achievement of the organization's objectives" (Freeman 1984, p. 46). ${ }^{1}$ In an earlier paper Freeman and Reed further distinguish two senses of "stakeholder". The "narrow" definition includes only those groups who are vital to the survival and success of the corporation. This would include suppliers, customers, employees, stockholders, the local community, managers, and probably also the government. The "wide definition" includes any group or individual who can affect or is affected by the corporation (Evan \& Freeman 1996, p. 259). This definition enlarges the notion considerably and somewhat surprisingly to include such entities as competitors, the environment, and future generations. This already may start to sound alarm bells: how can it be right for the firm to be managed partly for the interests of its competitors, especially in the light of important legal and moral restrictions on collusion, cartels, and price fixing? We will return to this important point below. 
The narrow and wide conceptions of a stakeholder each suggest a somewhat different route to justifying the claim that stakeholder interests must be served in the management of the corporation. Stakeholders in the narrow sense have all made a significant contribution to the success of the firm. Consequently, one might argue that the firm has obligations stemming from considerations of reciprocity and gratitude. Stakeholders in the wide sense are primarily those susceptible to being adversely or positively affected by the activities of the corporation. One can, therefore, imagine a justification for the obligations prescribed by stakeholder theory based either on consequentialist considerations of maximizing overall welfare, or perhaps on the rights of groups not to be harmed or interfered with in various ways.

In fact Evan and Freeman employ a different argument which purports to be Kantian in spirit and is linked immediately to questions of corporate governance: "Each person has the right to be treated, not as a means to some corporate end, but as an end in itself. If the modern corporation insists on treating others as means to an end, then at a minimum they must agree to and hence participate (or chose not to participate) in the decisions to be used as such" (Evan \& Freeman 1996, p. 258). In this paper I will not discuss the specifics of this argument and its supposedly Kantian derivation. Instead I will focus on the general form of the stakeholder theory which serves as a presupposition for all forms of the argument.

\section{Practical objections}

Our first thoughts about the stakeholder theory of the firm, however, are likely to involve practical questions. The managers of the firm, on this view, occupy an extraordinary and rather questionable moral position for they are both stakeholders themselves, and hence one of the groups whose interests are to be balanced, and also those who have to do the balancing. Their position is thus inherently one of conflict of interest. Given this, the mechanisms of accountability and control to which they would, on this view, have to be subject would be exceptionally strong. Indeed, as we shall see below, these mechanisms would be so strong and pervasive that they may be judged to be morally objectionable in their own right.

Elaine Sternberg has raised a further practical objection. She claims that the imposition of wide-ranging responsibility has, in practice, the effect of substantially diluting accountability: "a business that is accountable to all, is actually accountable to none: accountability that is diffuse, is effectively non-existent" (Sternberg 2000, p. 51) She goes on wryly, yet perceptively, to note that "some of the most prominent advocates of stakeholder theory have been just those with most to gain from avoiding accountability: business managers. By substituting a vague notion of "balancing interests" for a measurable standard of financial performance, stakeholder theory frees business managers to pursue their own ends" (Sternberg 2000, pp. 51-52).

Evan and Freeman admit that "the task of management in today's corporation is akin to that of King Solomon" (Evan \& Freeman 1996, p. 262). Nonetheless they seem to think that it is a task that may adequately be discharged by today's professional managers.

\section{The transcendental "I" of acquisition}

These practical objections are important, but I want to suggest that there is a deeper error in the stakeholder theory of the firm which stems from its problematic conception of the nature of the corporation, and moreover that this conception is shared by the Friedmanite shareholder value view of the firm. Ultimately both the shareholder value and the stakeholder theory of the firm end up making the idea of corporate social responsibility incoherent because they employ a vacuously thin conception of the nature of the corporation.

How can this be so? How can it be that the stakeholder theory in particular, which set out to provide a theoretical basis for corporate social responsibility, ends up making corporate social responsibility impossible or incoherent?

To understand how this happens we may start by examining how stakeholder theory conceives of the relationship between stakeholders and the corporation. Consider Evan and Freeman's diagrammatic presentation of the stakeholder model of the corporation (Fig. 1). 


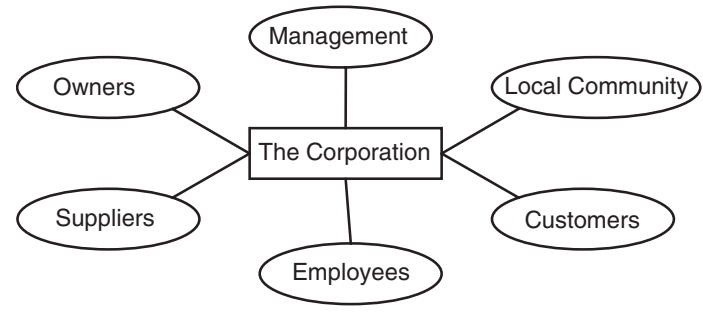

Figure 1. Evan and Freeman's stakeholder model of the corporation.

Source: Evan \& Freeman, 1996, p. 259.

The corporation is shown in the centre surrounded by its familiar (narrow) stakeholder groups at the end of spokes that represent reciprocal moral stakes: owners, management, local community, customers, employees, and suppliers. We may quibble about the details of this picture - where for instance are the creditors (perhaps under suppliers)? Are the moral stakes really reciprocal in each of these relationships? Do we really want to say, for example, that consumers have moral obligations to consider the interests of firms they buy from?

The real perplexity starts, however, when one asks what the box in the middle of the diagram marked "corporation" is actually thought to contain. What it contains is clearly unlike any corporation that we may have known or interacted with in the real world because it is an entity which is distinct from employees, managers, or owners. In fact, of course, the box demarcated "corporation" is empty, because as Evan and Freeman make clear, the corporation is simply an "abstract entity" or a "fiction" (Evan \& Freeman 1996, p. 261).

This abstracted conception of the firm bears certain similarities to Kant's conception of the transcendental or noumenal self which he develops in the Critique of Pure Reason (Kant 1787). Kant believed that it is necessary to posit the existence of a wholly abstract subject of experience to explain how the perceptions and thoughts of a human being are bound together as the experiences of one self-identical person; in other words how it can be that my various thoughts and experiences are all unified as mine. Kant called this abstract subject the "transcendental 'I' of apperception". This transcendental self is purely formal or abstract and hence empty; it can never be felt or touched or experienced because it is itself the subject of all experience.

While I do not claim that the notion of the firm plays any analogous conceptual role in stakeholder theory, the picture of the corporation posited as the starting point of stakeholder theory is similarly formal, abstract, and empty. It cannot be identified with either the interests or the persons of employees or managers, because it is their legal employer. It cannot be identified with shareholders, because it is what they own. We might call this abstract notion of the firm (with our tongues only slightly in our cheeks) the "transcendental 'I' of acquisition".

Now the purpose of stakeholder theory, of course, is not to rest with the abstract picture of the corporation as an empty and wholly formal entity. It is rather to enlarge the moral scope of the corporation to cover all stakeholder interests. It is important to understand, however, why the empty and formal conception of the corporation is the chosen starting point of this argument. By denying that the corporation is identified with the interests of any particular stakeholder group (e.g., owners or managers) the abstract view of the corporation creates the image of the firm standing, as it were, at the same moral distance to every stakeholder, just as in Evan and Freeman's diagram. From here it is possible to move via some moral argument (in Evan and Freeman's case it is a loosely Kantian argument) to the conclusion that the purpose of the corporation is to act as a forum for promoting and balancing the interests of all stakeholders.

But by constructing the argument in this way, the stakeholder theory undercuts the possibility of corporate responsibility itself. As I explained above, there are two necessary prerequisites for a viable account of corporate responsibility. The first is that we have some account of how the corporation can function as an intentional agent. The second is that the corporation must be capable of being held accountable and punished, which at the minimum implies that it must have real interests. On the abstract conception of the corporation, however, neither of these prerequisites can be met.

The corporation posited by stakeholder theory cannot be an intentional agent because, quite simply, it has no capacities of agency. 
According to the stakeholder theory, the corporation itself is simply "conceived as a forum of stakeholder interaction", and "as a vehicle for coordinating stakeholder interests" (Evan \& Freeman 1996, p. 262). As such, it has no capacity for deliberating, willing or acting, three features which are necessary constituents of moral agency. On the stakeholder theory one could no more speak of the moral responsibility of a particular corporation such as Shell or McDonalds, than one could speak of the moral responsibility of a particular political system such as Westminster democracy. Each are conceived as a set of formal mechanisms for resolving and balancing conflicts of interests. As such they could not themselves be the subject of moral responsibilities.

Similarly on this model the corporation cannot be said to possess interests. When Evan and Freeman describe the structural changes which would be required to bring corporate practice into line with the stakeholder theory, they talk of the election of a special director to the board called the "metaphysical director" whose job is to represent the interests of the corporation itself as opposed to the various stakeholder groups associated with it. But this is pure fantasy. Abstracted from the interests of owners, managers, employees, and customers, the corporation simply has no interests. For example when we speak of a corporation having an interest in expanding sales or gaining access to new markets, this is entirely derivative of the shareholders' interests in profits, which are conceived as external to the corporation. Since the corporation's status is purely abstract, it cannot be ascribed even the interest in its own continued existence. And yet unless an agent has interests, it cannot be meaningfully punished. So under the stakeholder theory, just as we are prevented from ascribing moral responsibilities to the corporation, we do not seem to be able to make sense of the idea of punishing the corporation or holding it accountable.

It is clear that stakeholder theory cannot serve as the basis for an account of corporate moral responsibility in the sense of providing an account of how corporations can have moral obligations. This is a surprising and somewhat disconcerting result, since most theorists have assumed that providing such an account is precisely the point of stakeholder theory.
But does this matter? Under stakeholder theory the obligation to serve the interests of stakeholders cannot be ascribed to corporations, but falls rather upon managers. It is managers who oversee the resources of the firm and are required to ensure that the interests of all stakeholders are maximized where possible and balanced when not. Perhaps it does not matter that corporate responsibility drops out of the picture so long as we maintain a strong conception of managerial responsibility. On this reading, stakeholder theory simply replaces a conception of corporate responsibility with one of managerial responsibility. Is there anything wrong with this?

Apart from the fact that it contradicts our intuitive understanding of business ethics (which, as I suggested above, makes central use of the concept of corporate moral responsibility), the most damaging objection to this way of proceeding is that raised by Milton Friedman himself. The objection is that this approach inappropriately and dangerously politicizes private business activity (Friedman 1993, p. 251ff). If managers are to properly fulfil the awesome responsibility of administering the interests of numerous stakeholder groups attributed to them by stakeholder theory, then they must be properly mandated to do so. Evan and Freeman rightly suppose that such a mandate could only be achieved by introducing some wide-ranging democratic reforms into the corporate governance of firms. They envision power within the corporation being transferred to a "stakeholder board of directors" consisting of representatives of five stakeholder groups plus one for the corporation itself, the "metaphysical director". Each director is to be elected by a "stakeholder assembly" with their own working rules and charters (Evan \& Freeman 1996, p. 264).

Friedman's point (generalized somewhat) is that by transforming the corporation into a forum for what are essentially political processes, stakeholder theory negates the idea of the business corporation understood as private enterprise - the pursuit of private interests by private means - altogether. All private enterprise under this model has becomes public enterprise, and the notion of a distinct sphere of private corporate activity and hence of corporate moral obligation evaporates. This really is Friedman's nightmare vision of corporate morality, in which all of commercial life, and by extension all 
private life, becomes subsumed within the realm of politics. ${ }^{2}$ So stakeholder theory negates the possibility of corporate ethics, not only in the sense of preventing us from attributing agency and interests to corporations, but in a deeper sense by denying the legitimacy of the sphere of private enterprise.

\section{Shareholder value theory}

What then, of Milton Friedman's own preferred alternative, the shareholder value theory? What conception of the corporation is presupposed by this account? Friedman himself is not entirely explicit on this point. But the most natural way of reading his argument is that it is based on the classic conception of the corporation, derived from legal theory, as the nexus of legal contracts among the owners of the factors of production and customers. On this conception the corporation is also conceived as an abstract and fictive entity, though one constituted by complex legal relations between persons. Such a conception accords with Friedman's claim that "only persons can have responsibilities" (Friedman 1993, p. 249) and on his insistence that positive moral responsibility in business is limited to those defined by the relationship between shareholders and management.

If this is correct, then it would appear that the stakeholder theory and the shareholder value theory are parallel in structure. Both arguments work by starting from an abstracted and formal conception of the corporation and by then arguing on independent grounds that management is under the obligation to run the firm exclusively for the benefit of a particular set of interests: shareholder interests for the shareholder value theorist, the collective and politically moderated interests of stakeholders, for the stakeholder theorist. But both views equally make the idea of corporate social responsibility itself incoherent.

On the shareholder value theory, the corporation is a formal entity which can have no moral obligations to non-shareholding stakeholders because of the special relationship between managers and owners. On the stakeholder theory, the corporation is a formal entity which can have no moral obligations because it is simply a political forum for balancing and distributing the interests of members.

But both views are inherently implausible. Both fail to capture the intuition that we can properly talk of the moral responsibility of corporations, not just of managers, and that the reason we may do so is that corporations are not wholly abstract legal entities, but concrete commercial and social entities which are managed for a determinate set of interests by determinate groups through determinate decision structures. If we are to provide an effective account of corporate moral responsibility, then we must start from a conception of the firm that is concrete rather than abstract. A viable account of corporate moral responsibility can only proceed by acknowledging, describing, and analyzing these determinate interests and relationships.

\section{The abstract conception of the corporation in competitive strategy}

Before exploring how this can be achieved I would like to approach this argument from a different angle, by examining how the abstract conception of the corporation operates in the theory of competitive strategy.

Michael Porter's Corporate Strategy is one of the seminal texts in the theory of competitive strategy. It provides a highly insightful and influential framework for analyzing the competitive structure of industries (Porter 1980). The financial returns which a company will be able to achieve over the long term within a given industry are determined, he argues, by the operation of five "competitive forces" namely: the rivalry among existing firms within an industry, the bargaining power of suppliers and buyers, the threat of new entrants into the industry and the threat of substitution to other products and services (Porter 1980, p. 4ff).

Porter's framework is proposed for the analysis of industries as a whole, but it is equally applicable to individual firms. Firms are competitive entities and the returns which they will be able to earn depend on the strength or weakness of the competitive entities with which they are interacting and competing. Porter's insight is that the entities which make up a firm's 
competitive environment go beyond the obvious existing industry competitors, and include potential new entrants to the marketplace, the producers of substitutable products, buyers (i.e., customers) and suppliers.

Now this observation has an important implication for normative stakeholder theory. We noted above that the suggestion that competitors should be considered as stakeholders, whose interests make moral claims upon the firm, is one which properly generates some discomfort for stakeholder theory. There are other words for managing a firm with the cooperation of competitors and with their interests in mind. These words are collusion, cartel, and price-fixing and they are criminal offences in most jurisdictions. This highlights the distinctive role played by competition in business ethics. Competition is not simply a discretionary activity for firms. Business corporations are morally obligated to engage in competition and they are morally prohibited from colluding with competitors so as to maximize shared profits. This obligation stems from the social benefits of business competition and the enormously harmful effects that ensue when competition fails.

This is not, of course, to say that firms have no moral obligations to competitors. Competitors owe each other a raft of negative moral obligations which constitute and specify the terms of fair competition. But they do not owe each other the obligation to maximize or balance each others' interests on the model of normative stakeholder theory. Generalizing from this we might say that the moral limits of stakeholder obligations are reached when one is dealing with competitors: competitors simply should not be treated as stakeholders in the term of normative stakeholder theory.

But as Porter's analysis shows us, the set of entities with which a corporation competes is significantly broader than the obvious existing industry competitors. It includes, for instance, suppliers and customers. Firms compete with suppliers by using their purchasing power to negotiate down price and they compete with customers by, among other things, establishing brands and imposing switching costs which enable them to maximise prices or reduce product quality. Now according to normative stakeholder theory, both suppliers and custo- mers are considered core "narrow" stakeholder groups, i.e., those for whose benefit the corporation is supposed in part to be run. But if it is true that a corporation has a moral obligation to compete and not collude with competitors, then the extent of stakeholder obligations owed by corporations to customers and suppliers will have to be severely circumscribed.

This sounds like the beginning of a powerful sceptical argument against numerous forms of commonly supposed corporate obligation. But I want to take the argument in a somewhat different direction. Let us pose the question the other way round. Instead of asking about the nature and extent of the competitors of the firm (which groups are properly considered competitors of the firm?), we may ask about the nature and extent of the competitive firm itself (exactly what is the entity which is engaged in the activity of competition, the entity at the centre of Porter's five forces?). To put this question another way, what is the subject of competition?

Customers and suppliers are external to the firm considered here as a subject of competition. They are external precisely because they are engaged in competition with the firm. But take this idea further: who are the suppliers of the firm? Obviously they include external contractors who provide raw materials and consumables to the firm. But they also include many groups who would generally be considered as internal to the firm. For example employees are suppliers of labour to the firm and they compete with the firm through wage bargaining. Management are simply a subset of employees and hence may also be considered as external to the firm considered as the subject of competition. What of shareholders and creditors? They are suppliers of capital to the firm, and they too compete with the firm in the sense that they attempt to extract maximum return from the firm (in terms, respectively, of interest payable and equity stake) for their investment.

The difficulty with this picture is obvious. It is the recurrence of the abstract conception of the corporation, the transcendental "I" of acquisition. In trying to gain an understanding of the nature of the firm as a subject of competition, we have ended up with a purely formal empty notion - a theoretical nexus of competition which is distinct from labour, management, or capital. 
But this conclusion completely misconceives the nature of the question we began by asking. The corporation, abstractly conceived in this way, could not be the subject of competition in the real world, for the simple reason that it cannot compete. It has neither labour power with which to produce goods and services, management staff to set policy, or capital with which to purchase plant and equipment.

This paradox also has an operational manifestation. A basic observation of much work in management strategy is that a significant source of competitive advantage lies in the capabilities and dispositions of management and staff. If management and staff are viewed (and view themselves) as competitively external to the firm, that is to say as contractual suppliers of labour and management to an entity which is fundamentally in a stance of competition towards them, then it is unlikely that they will perform with maximal commitment and energy. Managers and workers will only contribute effectively to corporate goals if they see themselves, at least to some extent, as internal rather than external to the competitive organization.

What this implies is that if a firm is to compete effectively then, simply as a matter of motivational effectiveness, its sphere of competition cannot be unlimited. It must "internalize", as it were, some groups which are considered as external competitors on Porter's analysis. In practice this means that a firm's relations to its employees will always be mixed, combining elements of competition (in wage bargaining for instance) and elements of cooperation and mutuality. A similar picture will emerge for each of a company's stakeholder groups, though the mix of cooperative and competitive elements will differ importantly in each case. The idea of an unlimited subject of competition is not only a theoretical abstraction - a logically empty formal entity - it is also a commercial absurdity.

\section{Towards a concrete conception of corporate moral responsibility}

This observation can help to move us towards a more viable conception of the firm as a subject of moral responsibility (and also strategic effec- tiveness). The stakeholder theory gives us a picture of the firm as a forum for cooperation amongst all stakeholder groups. The shareholder value theory, on the other hand, views the firm as solely representing the interests of shareholders and in a fundamentally competitive stance towards all other groups. I have argued that both theories are inadequate. Both views are a distortion of the reality of commercial and moral relations. A firm's relations with its stakeholders entail neither purely balancing and maximizing their interests (the cooperative picture), nor exclusively competing with them it is a complex mix of the two. If we imagine pure competitive relations and pure cooperative relations to exist at either end of a continuum, then it is possible to represent the typical array of stakeholder relations diagrammatically (Fig. 2).

It is important to realize that where a given stakeholder relationship falls on this continuum may be determined by both competitive strategy and ethical considerations and that, significantly, these two considerations often coincide. For example there are both commercial and ethical reasons why relations with industry competitors should be governed by competitive rather than cooperative principles. As we have seen there are both commercial and ethical reasons why employees must be treated with a kind of consideration and concern that is not appropriate for industry competitors.

More importantly still, this diagrammatic representation allows us to see the basis for a more concrete and realistic conception of the corporation as the subject of moral responsibility. As I have stressed, to have corporate moral responsibility we must have a conception of the corporation that allows corporate moral agency and intentionality, and that conceives of the corporation as having real interests and hence being capable of reward and punishment. We can begin to realise this if we associate the subject of corporate moral responsibility not with an abstract entity, but with the groups and individuals that de facto have control over the corporation and whose interests the corporation de facto represents and furthers. The dotted circle to the right demarcates the approximate de facto limits of the firm in the sense of identifying those groups who have most control over the actions and policy of the firm and whose interests are most directly represented by the 
firm. It is the management, employees, and (through their election of the board of directors) shareholders who have most power to direct the activities of the corporation. It is shareholders who, as the owners of the corporation, are primary beneficiaries of the activities of the corporation.

If the corporation is identified with this concrete set of agents and interests, rather than conceptualized as an abstract entity, then it is possible to meet the two prerequisites for generating an account of corporate moral responsibility: agency and interests capable of being adversely affected by punishment.

Firstly, it is possible to give an account of how corporations can have intentions and moral agency along the lines of Peter French's Corporate Internal Decision structure (CID) (French 1984). The CID is composed of two parts. The first is an organizational or responsibility flow chart, which describes the position, authority, and responsibility of managers within the organizational hierarchy. The second is a set of corporate decision rules, for example the articles of association, company policy and guidelines which determine how a decision may or must be made. French calls the organizational chart the grammar of corporate decision-making while the recognition rules provide its logic. Together they provide criteria for determining what is, and what is not, a properly constituted decision or action of the corporation. When a corporation undertakes a course of action or formulates a policy in accordance with the CID then this can be considered an intentional act of the corporation as a whole - one for which it can bear legal and moral responsibility.

Secondly, corporations can have interests chiefly because they are de facto operated to serve the interests of particular groups and individuals. Shareholders own the corporation and they are therefore morally and legally entitled to the surpluses generated by the corporation. The corporation also serves in a more circumscribed way the interests of managers and employees through its provision of wages, benefits, and meaningful work. When we speak of the interests of a corporation, this reflects the underlying interest of those who have a de facto claim on the corporation's products. If a corporation is punished by being fined, taxed, restricted in its operations, or broken up, this

More Competitive More Cooperative

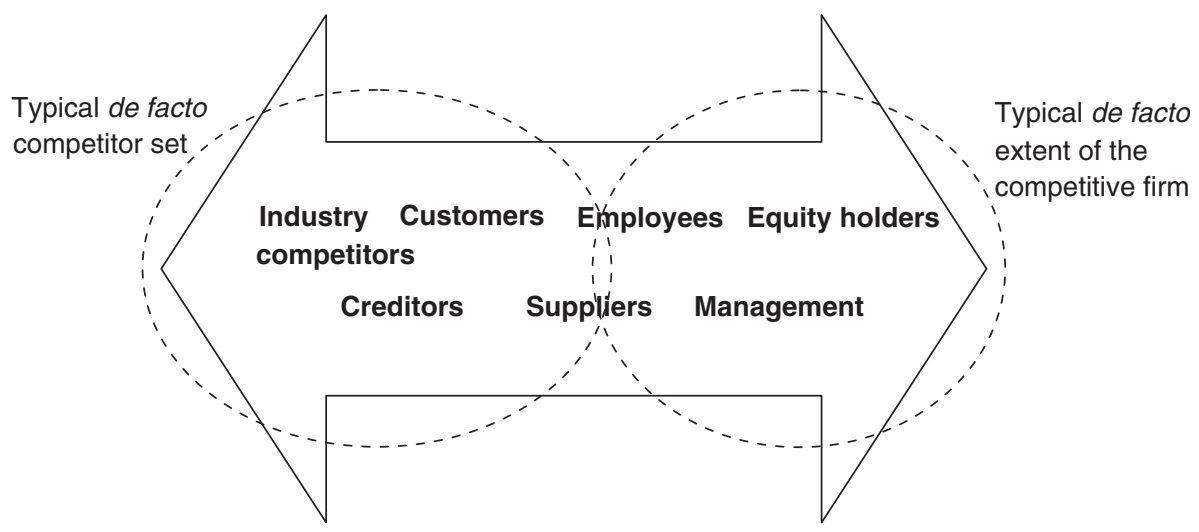

- Governed by negative moral obligations

-Conditioned by competitive forces
- Governed by positive as well as negative moral obligations

- Conditioned by political processes and moral relations (e.g. moral reciprocity and concern for interests)

FIGURE 2. The typical array of stakeholder relations. 
can properly be said to harm the corporation's interests because it harms the interests of those who have a de facto claim on the corporation: shareholders, managers and employees. A principal goal of corporate governance is therefore to align control over, and interest in, the corporation. The basic principle being that those whose interests are served by the corporation should have effective control over its activities and should also, therefore, suffer the punitive consequences of any corporate wrong-doing.

This account is highly schematic and obviously requires considerable development. But it seems a plausible way to approach one significant component of corporate moral responsibility - the obligations owed by corporations to groups external to the corporation such as external stakeholders. These obligations are not, and could not, be to maximize those interests as the stakeholder theory claims, not least because many of these groups are competitors of the firm. The corporation does, however, have significant negative obligations not to cause unjustified harm in pursuit of the interests it serves, and it can and should be liable to punishment if it violates those obligations.

But moral relations with groups external to the corporation are only one component of business ethics. Many issues involve conflicts between groups that are internal to the firm as here defined; between, for instance, management and shareholders, employees and management, or between different shareholder groups. In these cases relations ought not to be governed principally by competitive forces. These groups are all, to a significant degree, internal to the firm - they help to control it and share in its benefits. Different forms of obligation and mechanisms for resolving conflict are appropriate in these cases. It is plausible that here the appropriate image is much more like the stakeholder theory account of a political forum for balancing and maximizing interests.
To make matters more complex still, the dividing line between those groups normatively "internal" and "external" to the corporation is porous, variant, and often indeterminate. As the above diagram suggests, competition and cooperation are extreme elements on a continuum. Most relations in business will embody some complex mix of the two. This feature of business relations, always present to some extent, has been considerably amplified by a number of modern trends. Outsourcing and supply chain management, for example, blur the distinction between suppliers who are internal and those who are external to the firm. If this mixed view of business relations is correct, then a complete account of business ethics will be an extremely complex undertaking indeed. It will require describing and untangling the complex network of relations between individuals and groups that underlie the behaviour of corporations, and then applying and balancing two very different models of normative interaction and assessment.

What is clear is that this complex picture cannot be reduced to the simple structures of stakeholder or shareholder value theory. The undifferentiated political cum cooperative mechanisms proposed by stakeholder theory to govern the relations between all stakeholder groups fails to recognize the moral primacy of the claims of shareholders as owners of the corporation. On the other hand, shareholder value theory is mistaken in that it takes the moral claims of shareholders, and the obligations of managers as the agents of shareholders, to be exhaustive of business ethics. But, as I have argued, corporate moral responsibility exists in large measure because managers administer corporations to further the interests of shareholders. It is only because a corporation is administered by a determinate group of people that it can have agency. It is only because a corporation serves a determinate set of interests that it can be liable to punishment and reward.

\section{Notes}

1. The phrase "achievement of the organization's objectives" is unfortunate since it wrongly suggests that the effects of an activity that does not successfully achieve the organization's objec- tives, or is extraneous to those objectives, is excluded from the definition. Nonetheless the 
basic intention of the definition is clear.

2. Evan and Freeman apply this model only to large corporations, but it is unclear on their argument why it should not also be extended to all businesses. Even very small businesses, such as sole proprietorships, can affect the rights and interests of stakeholders, so it is unclear why they should not be subject to control by a stakeholder board.

\section{References}

Evan, W. M., and Freeman, E. 1996. "A stakeholder theory of the modern corporation: Kantian capitalism", In: Chryssides, G. D., and Kaler, J. H., eds, An Introduction to Business Ethics. London: Thomson Business Press, pp. 254-266.

Freeman, E. 1984. Strategic Management. A Stakeholder Approach. Boston: Pitman Press.
French, P. 1984. Collective and Corporate Responsibility. New York: Columbia University Press.

Friedman, M. 1993. "The social responsibility of business is to increase its profits", In: Chryssides, G. D., and Kaler, J. H., eds, An Introduction to Business Ethics. London: Thomson Business Press, pp. 249-254.

KANT, I. 1787. Kritik der reinigen Vernunft. $2^{\text {nd }}$ edition. [The Critique of Pure Reason. New York: St Martin's Press, 1965.].

Porter, M. E. 1980. Competitive Strategy: Techniques for Analyzing Industries and Competitors. New York: The Free Press.

Sternberg, E. 2000. Just Business. Business Ethics in Action. $2^{\text {nd }}$ edition. Oxford: Oxford University Press. 